MANCHESTER

1824

㐫过

Economics

Discussion Paper Series EDP-1201

\title{
On the Price Effects of Horizontal Mergers: A Theoretical Interpretation
}

\author{
Emilie Dargaud \\ Carlo Reggiani
}

January 2012

Economics

School of Social Sciences

The University of Manchester

Manchester M13 9PL 


\title{
On the Price Effects of Horizontal Mergers: A Theoretical Interpretation*
}

\author{
Emilie Dargaud ${ }^{\dagger} \quad$ Carlo Reggiani ${ }^{\ddagger}$
}

December 2011

\begin{abstract}
Horizontal mergers are usually under the scrutiny of antitrust authorities due to their potential undesirable effects on prices and consumer surplus. Ex-post evidence, however, suggests that not always these effects take place and even relevant mergers may end up having negligible price effects. The analysis of mergers in the context of non-localized spatial competition offers a further explanation of that evidence: in this framework both positive and zero price effects are possible outcomes of the merger activity.
\end{abstract}

JEL code: D43, L11, L13.

Keywords: horizontal mergers, price effects, spokes model.

${ }^{*}$ We would like to thank John Bone, Stefania Borla, Ramon Caminal, Bipasa Datta, Norman Ireland and Peter Simmons for precious comments and feedback.

${ }^{\dagger}$ CEMOI, Université de la Réunion, 15 Avenue René Cassin, BP 7151, 97715 Cedex 9, Saint Denis Messag; e-mail: edargaud@univ-reunion.fr.

${ }^{\ddagger}$ School of Social Sciences - Economics, University of Manchester, Manchester, M13 9PL, UK. Ph: +44(0)1612754516; e-mail: carlo.reggiani@manchester.ac.uk. 


\section{Introduction}

Antitrust authorities worldwide are highly concerned with the price effects of mergers (Whinston, 2007). When two or more firms operating in the same market merge, the concentration of the market increases and this may drive to undesirable increases in prices with a consequent damage for consumers. According to Weinberg (2008), "the agencies review mergers in an effort to identify and block mergers if they would increase prices". For these reasons several approaches have been developed in the literature and by the practitioners to evaluate the price effects: "event studies" based on the behaviour of the stock markets evaluation of the companies involved, "simulation studies" based on theoretical models of mergers and appropriately parametrized and "direct studies" of the price effects within a specific industry (Pautler, 2001; Weinberg, 2008). Although the literature mainly focuses on price increasing mergers as they affect consumers and society's welfare, a number of papers also provide ex-post evidence of little or no price effects of a merging activity. A common trait of the retrospective evidence available is that not always anti-competitive effects arise. This may be due to efficiency gains to be exploited and passed through to prices or simply to the fact that price effects are not significantly affecting consumers welfare. Ashenfelter and Hosken (2008) find that in two out of the five mergers they consider no substantial price effects were registered. In particular, the Aurora-Kraft syrup mergers had almost no effect while the Marathon-Ashland joint venture in the gasoline sector had negative (although non-significant) medium term effects on prices; the latter case is also discussed by Taylor and Hosken (2007) with similar conclusions. Ashenfelter et al. (2011) document Whirlpool's acquisition of Maytage, a merger of two large manufacturers of electrodomestics. They find no changes in the prices of washing machines and sensible price increase only for some categories of products. Simpson and Taylor (2008) analyse the effects of MAP's 1999 acquisition of Ultraman Diamond Shamrock's terminaling assets on retail prices in Michigan: they analyse gasoline prices in six cities for a period of five years and find no 
evidence that the transaction led to higher prices. Neumann and Sanderson (2007) analyse the Corus and WIC merger by collecting information from market participants through interviews, other studies and from public sources about post-merger conditions. Although their evidence might have a limited value, they conclude that price increases are mostly attributed to inflation. As already underlined, zero-price effects of mergers can be the result of efficiency gains that just compensate a proportional price increase: Connor et al. (1998) witnesses that this is not the only possibility. They analyse general hospitals' mergers and find a $5 \%$ price decrease in merging hospitals relative to non-merging ones. In addition, they find that costs also decrease by about 5\% in the merging hospitals, indicating an almost perfect pass-through of the cost-savings on prices. More in general, Ashenfelter et al. (2009) assert that the retrospective evidence gathered at date is not sufficient to conclude on the anti-competitive effects of mergers: even significant mergers not always have a sensible negative effect on consumers. This paper proposes a simple theoretical analysis of mergers in differentiated product industries which is consistent with the evidence of horizontal mergers producing substantial price effects and others whose effects are instead negligible.

The rest of the paper is organized as follows. Section 2 locates our contribution in the literature. Section 3 briefly reviews the spokes model and its properties. Mergers are introduced in section 4. Section 5, discusses the price effects of mergers, comparing the pre-merger with the post-merger equilibria. Concluding remarks follow in section 6 .

\section{Related literature and contribution}

We study the effects of horizontal mergers in the context of "non-localized" competition. The "traditional" approach to spatial competition uses the circular city model of Vickrey (1964), also referred to as the Salop (1979) model: one of its limits is to address only "localized" spatial competition (Rothschild, 2000). Chen and Riordan (2007a) develop a new analytical 
tool to analyze spatial differentiation which naturally fits to the idea of "non-localized" competition, the spokes model. In this model firms are located at the extreme of a market constituted of several spokes all linked at a common centre. There may be more spokes than firms (Chen and Riordan, 2007a) or as many spokes as firms (Caminal and Claici, 2007). The model has two main properties. First, it allows multi-firm spatial competition with no neighbouring effects; second, it captures monopolistic competition à $l a$ Chamberlin as the number of firms tends to infinity. The model is particularly useful to analyze markets in which consumers have a strong preference for a specific brand while being rather indifferent among alternatives: natural examples are markets for a composite good that requires original parts to be completed or repaired. In a merger context, the spokes approach has a desirable feature: competition is non-localized and in equilibrium all firms are competing against each other. The effect of a merger is then to reduce the intensity of competition. The price effect, however, depends on which part of the market firms are targeting when setting prices. The demand for the firms' product is composed of several segments characterized by different elasticities. There exist, then, equilibria in which price effects are important and also imply demand effects that lead to increased transportation costs and, consequently, to negative welfare effects. However, when firms target a "kink" of the demand function, equilibria as in Economides (1989, 1993) arise and there are no price effects. The results can be interpreted as a possible explanation of the mixed evidence on the mergers effects proposed in the empirical literature.

The contribution of this paper is related to the literature on endogenous mergers. The goal of many papers on the topic is to solve the paradoxes posed by the game theoretical analysis of mergers and coalition formation. One of the paradoxes is that under price competition and differentiated products mergers are always profitable for insiders (Deneckere and Davidson, 1985). However, the equilibrium displays free-riding properties: "outsiders" earn higher profits than "insiders". This property also characterizes our analysis: in the regions where prices are increasing following a merger, ousiders' 
prices and profits raise more than insiders'. In other instances, however, prices do not increase. Brito (2003) considers mergers in the context of the circular city. He shows that even if market power is the motivation for a merger, firms may want to be insiders (preemptive merger) and the impact of the merger on the rival firms depends on their location. Firms may prefer to be insiders even if some outsiders benefit more (but others less). In this context, he finds that mergers have relevant impacts on prices only if one of the neighbouring firms takes part into it. Our zero-price effect result, however, is not related to proximity of firms, that plays no relevant role in the spokes model. Braid (1999) considers two-dimensional competition between firms located on a grid: the price effects of a merger are lower due to a reduction in the benefits of merging for insiders. As opposed to the standard single dimension, this feature implies that the incentives to raise prices are spread in different directions.

Our results contribute to the rapidly flourishing literature adopting the spokes model as a tool for analysis of multi-firm differentiated product competition $^{1}$. The analysis of the model is extended to allow for asymmetric firms. Taking into account asymmetries may be quite complex in other models of product differentiation as the circular city model (Brito, 2003; Borla, 2008; Syverson, 2004; Vogel, 2008; Alderighi and Piga, forthcoming). In our approach the non-localized nature of competition avoids complex feedback effects on prices of the neighbouring firms; this property may strengthen the case for the spokes model as a convenient and reasonable alternative to the circular city in addressing spatial competition between $n$ firms.

\footnotetext{
${ }^{1}$ The spokes model is used, between others, by Caminal and Claici (2007) in the context of loyalty rewarding schemes, by Caminal and Granero (2008) to study the provision of quality by multi-product firms, by Ganuza and Hauk (2005) to address allocation of ideas in tournaments, by Chen and Riordan (2007b) on vertical integration.
} 


\section{The Framework}

Consider the model introduced by Chen and Riordan (2007a). The market has a spatial structure made up of $N$ spokes of constant length $1 / 2$, with a common centre; $n$ firms are on the market, with $n \leq N$ exogenously given. Each firm is located at the extreme of its own spoke and supplies an homogeneous good: transportation costs are the only source of differentiation. Customers are uniformly distributed over all the $N$ spokes. All consumers evaluate one unit of the good $v$, the transport cost is normalized to one and the marginal cost to zero.

\section{[FIGURE 1 ABOUT HERE]}

Tractability requires that consumers only like the brand located on their spoke and a finite subset of the $N-1$ alternative brands: as Chen and Riordan (2007a) it is assumed that any random consumer on a spoke likes only one alternative brand. Notice that if $n<N$, a consumer may not find available the first or the second brand or both: in that case the market is not fully covered.

The profit function of a given firm $i$ is:

$$
\pi_{i}\left(p_{i}, p_{-i}\right)=p_{i} D\left(p_{i}, p_{-i}\right)
$$

From firm $i$ 's viewpoint there are different types of customers ${ }^{2}$ :

1. Customers on $i$-th firm's spoke that have one of the remaining firms as an alternative. The demand from this group is defined by identifying the location $\hat{x}$ of the consumers who are indifferent between buying from $i$ or buying from the rival firm $\alpha$ :

$$
\hat{x}=\max \left\{\min \left\{\frac{1}{2}+\frac{p_{\alpha}-p_{i}}{2} ; 1\right\} 0\right\}
$$

The constraints imposed require the customer to be located on either of the spokes and not outside.

\footnotetext{
${ }^{2}$ Despite recognizing different types of customers, firms use a unique price and are not allowed any kind of price discrimination.
} 
2. Customers on the $i$-th firm's spoke who do not have an existing alternative brand and customers who do not have a first favorite brand but have $i$ as a second favorite. The marginal consumer in the set of these two types is identified by:

$$
\check{x}=\max \left\{\min \left\{v-p_{i}, 1\right\}, 0\right\}
$$

Simplifying the constraints, the demand function is defined by the following segments:

$D_{i}\left(p_{i}, p_{-i}\right)=\left\{\begin{array}{ccc}\frac{2}{N} \frac{1}{N-1} \sum_{\alpha \neq i}\left(\frac{1}{2}+\frac{p_{\alpha}-p_{i}}{2}\right)+\frac{2}{N} \frac{N-n}{N-1}\left(v-p_{i}\right) & \text { if } & \frac{1}{2} \leq v-p_{i} \leq 1 \\ \frac{2}{N} \frac{1}{N-1} \sum_{\alpha \neq i}\left(\frac{1}{2}+\frac{p_{\alpha}-p_{i}}{2}\right)+\frac{2}{N} \frac{N-n}{N-1} & \text { if } & v-p_{i}>1\end{array}\right.$

where $2 / N$ is the density of consumers on each spoke, $1 /(N-1)$ is the probability of firm $\alpha$ being a customers' second favorite brand and ( $N-$ $n) /(N-1)$ is the probability of a consumer having no first or no second favorite brand available. The following regularity conditions need to be satisfied: $\left|p_{\alpha}-p_{i}\right|<1 \quad \forall \alpha \neq i$ and $v-p_{i} \geq 1 / 2$ to ensure that competition between firms occurs.

The first order conditions identifying the equilibrium prices are given by:

$$
\frac{\partial \pi_{i}}{\partial p_{i}}=D_{i}\left(p_{i}, p_{-i}\right)+p_{i} \frac{\partial D_{i}\left(p_{i}, p_{-i}\right)}{\partial p_{i}}=0
$$

Given the definition of the demand and profit functions, it can be checked that there exist four possible equilibrium regions ${ }^{3}$.

[FIGURE 2 ABOUT HERE]

The equilibrium regions are characterized depending on $v$, the parameter capturing consumers' evaluation of the good; the equilibrium prices before a merger takes place, $p_{b m}^{*}$ are defined as in Table 1:

\footnotetext{
${ }^{3}$ The details of the derivations can be found in Proposition 1 of Chen and Riordan (2007).
} 
Table 1. Before Merger Equilibrium Prices.

\begin{tabular}{|c|c|c|}
\hline Region & Range $\left(v_{\min }, v_{\max }\right)$ & $p_{b m}^{*}$ \\
\hline $1 \mathrm{bm}$ & {$\left[\frac{2(N-1)}{n-1} ; 2 \frac{N-1}{n-1}+\frac{2 N-n-1}{2(N-n)}\right]$} & $\frac{(2 N-n-1)}{n-1}$ \\
\hline $2 \mathrm{bm}$ & {$\left[2 ; \frac{2(N-1)}{n-1}[\right.$} & $v-1$ \\
\hline $3 \mathrm{bm}$ & {$\left[\frac{1}{2} \frac{4 N-n-3}{2 N-n-1} ; 2[\right.$} & $\frac{2 v(N-n)+(n-1)}{4 N-3 n-1}$ \\
\hline $4 \mathrm{bm}$ & {$\left[1 ; \frac{1}{2} \frac{4 N-n-3}{2 N-n-1}[\right.$} & $v-\frac{1}{2}$ \\
\hline
\end{tabular}

As illustrated in Figure 2 the price is a non-decreasing function of the value of the good $v$. For values of $v$ above $v_{1 U}^{b m}=2 \frac{N-1}{n-1}+\frac{(2 N-n-1)}{2(N-n)}$ a pure strategy equilibrium of the game does not exist: a too large valuation of the good implies firms have a unilateral incentive to raise their price to $p=v-1$ which is however not an equilibrium either. Our analysis will focus on the equilibrium regions $1 \mathrm{bm}-4 \mathrm{bm}$ : more details on the features of these equilibria are provided in Chen and Riordan (2007a) and are also discussed in Section 5.2. For even lower values of $v$ an equilibrium would exist but all firms would be local monopolists serving only part of the consumers located on their spoke.

\section{Horizontal Mergers}

Following the literature, it is assumed that the merging firms maximize their joint profits. We abstract from bargaining considerations: the after merger profits are split in equal parts between the participating firms. In other words, the only effect of a merger is to create a multi-product firm: the merging firms supply their product independently but they adopt joint decisions on their prices to maximize joint profits. Hence, Caminal and Granero (forthcoming), who explicitly address the role of multi-product firms in supplying variety, is the closest paper to ours. Their analysis considers a multi-product firm competing against a fringe in the equivalent of Region $1 \mathrm{bm}$ above; in what follows, instead, after-merger asymmetric competition is analyzed in all equilibrium regions. Moreover, our focus is on the 
price effects rather than on the market provision of variety.

\subsection{The Effects of a Merger}

Suppose that a merger of $k$ of the $n$ firms has taken place creating $M$. Denote by $i \in I=\{1, \ldots, k\}$ a firm belonging to $M$. All other firms are symmetric and indexed by $i \in O=\{k+1, \ldots, n\}$. Let us denote by $S$ the set of all firms $(S=I \cup O)$. In a market featuring $N$ spokes, the number of active firms reduces to $m=n-k+1$.

Focus first on the merged firms who constituted $M$. The following equation:

$$
v-p_{i}-x=v-p_{j}-(1-x) \quad \forall i \in I, \forall j \in S, \forall j \neq i
$$

still identifies the indifferent customers who have an alternative brand existing on the market and the set of indifferent consumers is described by:

$$
\hat{x}_{i j}=\max \left\{\min \left\{\frac{1}{2}+\frac{p_{j}-p_{i}}{2} ; 1\right\} 0\right\} \forall i \in I, \forall j \in S, \forall j \neq i
$$

Notice, however, that now there are two subsets of indifferent consumers: consumers whose other brand is supplied by one of the other firms taking part to the merger $(j \in M, j \neq i)$ and consumers whose other brand is supplied by one of the outsiders $(j \in O)$. Indifferent customers with no kind of alternative brand are still identified by:

$$
\check{x}_{i}=\max \left\{\min \left\{v-p_{i}, 1\right\}, 0\right\} \quad \forall i \in I
$$

To sum up, from the perspective of one of the firms who took part to the merger and constituted firm $M$ there are three types of customers after the merger with the following probabilities:

1. $\frac{k-1}{N-1}$ : probability that customers have their second favourite brand supplied by factories located on other spokes but belonging to $M$, the firm resulting from the merger;

2. $\frac{n-k}{N-1}$ : probability that customers have an alternative brand not supplied by other factories affiliated to $M$; 
3. $\frac{N-n}{N-1}$ : probability that customers do not have a second favourite brand.

It can be noticed that the merger creates no market expansion effect: the agents that do not have a first or a second favourite brand available are still excluded: the fraction of this type of consumers is unaffected by the merging activity.

The demand function of the merger $M$ is defined by the sum of the segments served by the $k$ firms. Proceeding in a similar way as in the benchmark case, the demand for each of the $k$ segments is given by:

$$
D_{i}\left(p_{i}, p_{-i}\right)=\left\{\begin{array}{c}
\frac{2}{N} \frac{1}{N-1} \sum_{\substack{\alpha=1 \\
\alpha \neq i}}^{k}\left(\frac{1}{2}+\frac{p_{\alpha}-p_{i}}{2}\right)+\frac{2}{N} \frac{1}{N-1} \sum_{\alpha=k+1}^{n}\left(\frac{1}{2}+\frac{p_{\alpha}-p_{i}}{2}\right)+\frac{2}{N} \frac{N-n}{N-1}\left(v-p_{i}\right) \\
\text { if } \frac{1}{2} \leq v-p_{i} \leq 1 \\
\frac{2}{N} \frac{1}{N-1} \sum_{\substack{\alpha=1 \\
\alpha \neq i}}^{k}\left(\frac{1}{2}+\frac{p_{\alpha}-p_{i}}{2}\right)+\frac{2}{N} \frac{1}{N-1} \sum_{\alpha=k+1}^{n}\left(\frac{1}{2}+\frac{p_{\alpha}-p_{i}}{2}\right)+\frac{2}{N} \frac{N-n}{N-1} \\
\text { if } v-p_{i}>1
\end{array}\right.
$$

The first term between square brackets represents consumers with both favourite brands being supplied by $M$. The second term represents consumers whose second favourite brand is supplied by one of the outsider firms. The third term identifies the demand of the consumers whose only desired brand is supplied by firm $i$. The demand of each of these segments is weighted by the respective probabilities of a given consumer being one of the three possible types recalled. 
Turning to outsiders, their demand is:

$$
D_{j}\left(p_{j}, p_{-j}\right)=\left\{\begin{array}{c}
\frac{2}{N} \frac{1}{N-1} \sum_{\alpha=1}^{k}\left(\frac{1}{2}+\frac{p_{\alpha}-p_{j}}{2}\right)+\frac{2}{N} \frac{1}{N-1} \sum_{\substack{\alpha=k+1 \\
\alpha \neq j}}^{n}\left(\frac{1}{2}+\frac{p_{\alpha}-p_{j}}{2}\right)+\frac{2}{N} \frac{N-n}{N-1}\left(v-p_{j}\right) \\
\text { if } \frac{1}{2} \leq v-p_{j} \leq 1 \\
\frac{2}{N} \frac{1}{N-1} \sum_{\alpha=1}^{k}\left(\frac{1}{2}+\frac{p_{\alpha}-p_{j}}{2}\right)+\frac{2}{N} \frac{1}{N-1} \sum_{\substack{\alpha=k+1 \\
\alpha \neq j}}^{n}\left(\frac{1}{2}+\frac{p_{\alpha}-p_{j}}{2}\right)+\frac{2}{N} \frac{N-n}{N-1} \\
\text { if } v-p_{j}>1
\end{array}\right.
$$

The three terms represent, respectively, the demand faced from consumers who have as other favourite a brand supplied by firms in $M$, consumers who have as other favourite a brand supplied by another non-merged firm and consumers whose only desired brand is supplied by the firm. The profit functions for the merged entity and for each outsider are respectively:

$$
\begin{gathered}
\pi_{M}=\sum_{\alpha=1}^{k} p_{\alpha} D_{\alpha}\left(p_{\alpha}, p_{-\alpha}\right) \\
\pi_{j}=p_{j} D_{j}\left(p_{j}, p_{-j}\right) \quad \forall j \in O
\end{gathered}
$$

The first order conditions for the merged and the non-merged firms are, respectively:

$$
\begin{aligned}
& \frac{\partial \pi_{i}}{\partial p_{i}}=D_{i}\left(p_{i}, p_{-i}\right)+p_{i} \frac{\partial D_{i}\left(p_{i}, p_{-i}\right)}{\partial p_{i}}+\sum_{\substack{\alpha=1 \\
\alpha \neq i}}^{k} p_{\alpha} \frac{\partial D_{\alpha}\left(p_{\alpha}, p_{-\alpha}\right)}{\partial p_{i}}=0 \quad \forall i \\
& \frac{\partial \pi_{j}}{\partial p_{j}}=D_{j}\left(p_{j}, p_{-j}\right)+p_{j} \frac{\partial D_{j}\left(p_{j}, p_{-j}\right)}{\partial p_{j}}=0 \quad \forall j, i \in I, j \in O
\end{aligned}
$$

The first order conditions of the merged and the non-merged firms can be compared. The effect of the merger is to lead each of the participating firms to internalize the externalities imposed by one's own price choices on the demand for other brands in the merger. This property, first illustrated by Deneckere and Davidson (1985), plays an important role in determining 
the results and it is further discussed in Section 4. As in the benchmark, regularity conditions, i.e. $\left|p_{\alpha}-p_{i}\right|<1 \forall \alpha \in I, \forall i \in I, \alpha \neq i$, have to be imposed before turning to the analysis of the equilibria and of the effects of the merger on prices and profits.

\subsection{The After-Merger Equilibrium}

The equilibrium prices for the merged and non-merged firms, denoted by $p_{m}^{*}$ and $p_{n m}^{*}$ respectively, are reported in Table 2 .

\section{Table 2. Merged Firms' Equilibrium Prices}

\begin{tabular}{|c|c|c|c|}
\hline Region & Range & $p_{m}^{*}$ & $p_{n m}^{*}$ \\
\hline 1am & {$\left[v_{1 D}^{a m} ; v_{1 U}^{a m}\right]$} & $\frac{(2 N-n-1)(2 n-1)}{(n-k)(2 n+k-2)}$ & $\frac{(2 N-n-1)(2 n-k)}{(n-k)(2 n+k-2)}$ \\
\hline 2am & {$\left[v_{2 D}^{a m} ; v_{2 U}^{a m}[\right.$} & $v-1$ & $v-1$ \\
\hline $3 \mathrm{am}$ & {$\left[v_{3 D}^{a m} ; v_{3 U}^{a m}[\right.$} & $\frac{(2 v N-2 v n+n-1)(4 N-2 n-1)}{16 N^{2}-20 N n+4 N k+4 N+6 n^{2}+3 n k+2 n-k^{2}+2 k}$ & $\frac{(2 v N-2 v n+n-1)(4 N-2 n-k)}{16 N^{2}-20 N n-4 N k-4 N+6 n^{2}+3 n k+2 n-k^{2}+2 k}$ \\
\hline 4am & {$\left[v_{4 D}^{a m} ; v_{4 U}^{a m}[\right.$} & $v-\frac{1}{2}$ & $v-\frac{1}{2}$ \\
\hline
\end{tabular}

All the details on the identification of the after-merger equilibria and the range of parameters for which they hold are reported in the Appendix. Some intuition, however, can be provided on how the results are obtained. The derivation of the price expression is quite straightforward using the demand functions identified by (2) and (3). The range of values for which the after merger equilibrium regions hold is identified by checking under what conditions firms have a possible deviation. At each equilibrium price, firms have potentially different deviations and, consequently, the values of $v$ that ensure such deviations are not profitable may differ. More in details, both outsiders and the firms composing the merger $M$ should not have an incentive to change their price; further, it has also to be verified that an insider has not an incentive to deviate unilaterally. The range for which the regions are defined, then, it is given by the intersection of the values of $v$ for which a given candidate price vector is indeed an equilibrium and none of the possible deviations is profitable. 


\section{$5 \quad$ Results and Discussion}

\subsection{The main result}

Bringing together the results of the pre-merger benchmark situation in Section 2 and the post-merger equilibria in Section 3, we identify four equilibrium regions. These regions can be seen as the analog of the four equilibrium regions analyzed by Chen and Riordan (2007a): the values of parameters corresponding to each region is given by the appropriate boundary between the ones defining the before merger, the merged and non merged firms equilibria. As we shall see, equilibria in these regions also share the same properties of the ones in Chen and Riordan (2007a), briefly recalled in Section 3. The four equilibrium regions we focus on are defined in terms of the parameter $v$ as:

$$
\begin{array}{ll}
\text { Region } 1 & v_{1 D}<v \leq v_{1 U} \\
\text { Region 2 } & v_{2 D}<v \leq v_{2 U} \\
\text { Region 3 } & v_{3 D}<v \leq v_{3 U} \\
\text { Region } 4 & v_{4 D}<v \leq v_{4 U}
\end{array}
$$

The analysis proposed focuses on the comparison of the equilibrium prices before and after the merger as defined in Section 3 and 4 in Regions 1-4 defined above. Proposition 1 states the main result of the paper.

Proposition 1 A merger leads to an increase in the market price of all firms in Region 1 and Region 3; it has no price effect in Region 2 and Region 4.

Proof In Region 1 the difference between the pre- and post-merger equilibria prices are:

$$
\begin{aligned}
p_{m}^{*}-p_{b m}^{*} & =(k-1)(n+k-1) \frac{2 N-n-1}{(n-1)(n-k)(2 n+k-2)} \\
p_{n m}^{*}-p_{b m}^{*} & =k(k-1) \frac{2 N-n-1}{(n-1)(n-k)(k+2 n-2)}
\end{aligned}
$$


As $k<n$, both are strictly positive. Then $p_{a m}^{*}>p_{b m}^{*}$. In Region 2 it is immediate to verify that $p_{m}^{*}=p_{n m}^{*}=p_{b m}^{*}=v-1$. In Region 3 , the price differentials are:

$p_{m}^{*}-p_{b m}^{*}=(k-1) \frac{4 N-3 n+k-1}{4 N-3 n-1} \frac{2 N v-2 n v+n-1}{16 N^{2}-4 N k-20 N n-4 N-k^{2}+3 k n+2 k+6 n^{2}+2 n}$

and

$p_{n m}^{*}-p_{b m}^{*}=\frac{k(k-1)}{4 N-3 n-1} \frac{2 N v-2 n v+n-1}{16 N^{2}-4 N k-20 N n-4 N-k^{2}+3 k n+2 k+6 n^{2}+2 n}$

As $k<n \leq N$, both $p_{m}^{*}$ and $p_{n m}^{*}$ are higher than $p_{b m}^{*}$. In Region 4, $p_{m}^{*}=p_{n m}^{*}=p_{b m}^{*}=v-\frac{1}{2}$. Q.E.D.

The results in Proposition 1 are graphically illustrated in Figure 3. Before and after-merger prices are plotted in the four equilibrium regions ${ }^{4}$. As it can be seen, in Region 1 and 3 the after-merger market price dominates the before merger price; in Region 2 and 4 the two prices coincide.

\section{[FIGURE 3 ABOUT HERE]}

\subsection{Discussion}

Proposition 1 states that in two of the equilibrium regions prices increase as a consequence of the merger while this is not the case for the remaining two regions. We shall first describe the mechanisms that lead to this result before providing an interpretation.

In Region 1, "standard" oligopolistic competition takes place: as the best response functions are upwards sloping, both insiders and outsiders raise their prices, creating an overall increase of prices and earning higher profits compared with the benchmark situation. The intuition provided in Deneckere and Davidson (1985) applies to the spokes model too: as a given outsider faces competition from both the merged entity and the other outsiders. Then, it shares with a given insider $n-2$ competitors. But they both

\footnotetext{
${ }^{4}$ The after merger price is defined as the average of the prices of insider and outsider firms, with the market shares as weights.
} 
face another competitor. For the outsider firm this competitor is a member of the merged entity, so a firm charging a higher price. The insider, on the other hand, faces competition of another outsider firm, which is charging a lower price. This implies that outsiders face less fierce competition and their profits dominate the ones of insiders.

In Region 2 a "kinked equilibrium" takes place as firms concentrate on extracting surplus on consumers who do not have a second favourite brand and are indifferent between buying or not. For this reason, the merger does not affect prices and profits. The same amount of consumers takes part to the market and prices are unaffected.

Region 3 features a price increase similar to Region 1: the reason, however, is less intuitive in this case. Competition in this region implies extracting all surplus from the marginal consumer who lacks a second alternative brand. A consequence of this feature is that the elasticity of demand is larger on the monopolistic segment; this leads to price increasing competition. Despite this, the mechanisms as in region 1 are in operation: the best response functions are still upward sloping so that prices of both insiders and outsiders increase, leading also to an increase in profits with respect to the benchmark situation.

In Region 4 the "kinked equilibrium" is of a different type: firms focus their attention on the indifferent consumers who have its brand as a first choice. As in Region 3 also in this region not all consumers with at least one favourite brand are served. But as in Region 2 the kinked nature of the equilibrium implies the prices remain unchanged even when a merger takes place.

The analysis of the four equilibrium regions has shown how several economic mechanisms operate in the spokes model. These mechanisms determine the price effects of an horizontal merger between firms. The results can be interpreted as follows: when genuine price competition is in operation, as in Region 1 and 3, then the "free-riding" property of the equilibrium takes place and the classical price increase result is confirmed. Such price effects imply that mergers have a negative impact not only on consumers but 
also on overall welfare. Asymmetric price increases are reflected on different equilibrium demand shares for different firms: this leads to an increase of overall transport costs, impacting negatively on welfare. "Kinked equilibria", however, take place in Region 2 and 4 and the equilibrium prices are independent of whether a subset of firms merge. In other words, when firms target a specific key segment of the market mergers do not have any price effect. The results, then, provide the policy maker with an important message. If a market is characterized by product differentiation and firms compete in prices, then a merger may not have detrimental effects for consumers and welfare. Instead, it was shown that for a non-negligible subset of the parameter space, mergers do not have any price effect at all. The results of the model seem consistent with the "ex-post" empirical evidence that not all mergers have important price effects, even when cost synergies do not play a key role.

The regions in which no price effect takes place do not capture a peculiar or special case. First of all, the size of the sub-space of parameters for which such equilibria take place is non negligible: this does not sensibly differ from the size of the other two regions. Secondly, in Region 4 firms focus on the marginal consumer who does not have an alternative brand and hence they only serve consumers on their own spoke; however, in Region 2, firms serve all types of consumers apart from the ones which would be cut out of the market in any case because none of the brands they like is available. In this sense competition between firms is fully in operation. Finally, it is not uncommon in the business world to observe firms targeting a specific class of (marginal) consumers as in our kinked equilibria.

The four regions discussed do not of course exhaust the space of parameters; further regions can be identified as the shadowed areas in Figure 3. We do not present the analysis for the remaining combinations of the parameters, i.e. the shaded regions in Figure 3. The results in those regions are quantitatively different from what we presented in this paper; qualitatively, however, they are similar and do not add to our understanding and interpretation of the price effects. In those regions, in fact, a price increase 
takes place following a merger in a similar fashion and for the same reasons as in Region 1 and Region 3 presented above.

\section{Conclusions}

Antitrust authorities focus much of their attention on the price effects of mergers: when two or more firms operating in the same market merge, the concentration of the market increases and this may drive to undesirable price effects. This paper provides a simple theoretical interpretation of the price effects of horizontal mergers which seems consistent with the empirical evidence: many mergers may have an important impact on prices but cases of negligible price effects are not rare either. Negligible price effects may be the outcome of cost synergies between the merged firms or simply of market interaction: our paper provides a theoretical underpinning for the latter case. The results are provided through the analysis of horizontal mergers in a context of spatial but non-localized competition: two key features of the spokes model, a recently introduced tool to address non-localized competition, are that proximity between firms plays no role and that not all spokes may feature a firm located on it. These properties allow to identify four types of equilibria with different features. In two of the equilibria, sensible price effects take place and the "free riding" mechanism described by Deneckere and Davidson (1985) is in operation. The merger modifies firms' reaction functions and drives both insiders and outsiders to raise their prices, with consequent harm to consumers and overall welfare. The latest effect operates through increased transportation costs due to the asymmetric demand effects of price increases. The two remaining equilibria, however, have different properties: in those, firms focus only on a specific type of consumer. Mergers then have no effects on prices, which are simply determined by a "kink" in the demand function that is targeted. The results, then, suggest that a merger will not necessarily imply a sharp increase in the price level: whether this is the case or not will actually depend on the type of consumers that firms are targeting when setting their prices. 
The results provided do not exhaust the applicability of the spokes model for the analysis of the effects of horizontal mergers. First, in our framework free entry implies no incentives to merge: firms paying a fixed fee would occupy the empty spokes until the profits are driven to zero or all spokes are taken; in both cases, a merger would not take place: a more relaxed pricing environment would induce further entry with the possibility that merged firms' profits go negative. However, the model can be extended to allow for heterogenous entry cost: for example, entrants may pay a higher fee than firms already on the market. Secondly, the spokes model can be used to address some of the questions posed by the endogenous mergers literature. Firms might differ in two dimensions: marginal cost and the number of varieties produced. In such a setting, one could evaluate which firms would merge and with what consequences. For example, as in Pita Barros (1998) and Socorro (2004), a merger between some firms with asymmetric production costs may imply that the merged firms can produce at a costs equal to the most efficient of its participants. Thus a merger entails a rationalisation gain since production can be re-allocated from a high-cost to a low-cost plant. The evaluation of the effects of similar mergers in the context of the spokes model is an interesting topic for future research. 


\section{References}

[1] Alderighi M. and C. Piga (forthcoming), Localized Competition, Heterogeneous Firms and Vertical Relations, Journal of Industrial Economics.

[2] Ashenfelter O. and D. Hosken (2008), The Effect of Mergers on Consumer Prices: Evidence from Five Selected Case Studies, NBER Working Paper 13859 .

[3] Ashenfelter O., Hosken D. and M. Weinberg (2009), Generating Evidence to Guide Merger Enforcement, NBER Working Paper 14798.

[4] Ashenfelter O., Hosken D. and M. Weinberg (2011), The price effects of a large merger of manufacturers: a case study of Matyag-Whirlpool, SSRN Working paper.

[5] Borla S. (2008), Spatial Competition and Merging Incentives when Firms Produce Complements, University of York, mimeo.

[6] Braid R.M. (1999), The Price and Profit Effects of Mergers in Two Dimensional Spatial Competition, Economics Letters, vol. 62, 113-119.

[7] Brito D. (2003), Preemptive Mergers under Spatial Competition , International Journal of Industrial Organization, vol. 21, 1601-1622.

[8] Caminal R. and A. Claici (2007), Are Loyalty Rewarding Schemes AntiCompetitive?, International Journal of Industrial Organization, vol. 25(4), 657-674.

[9] Caminal R. and L.M. Granero (forthcoming), Multi-product firms and Product Variety, Economica.

[10] Chen Y. and M. Riordan (2007a), Price and Variety in the Spokes Model, Economic Journal, vol.117, 897-921.

[11] Chen Y. and M. Riordan (2007b), Vertical Integration, Exclusive Dealing and Ex-Post Cartelization, Rand Journal of Economics, vol.38, 1-21. 
[12] Connor R., Feldman R. and B. Dowd (1998), The Effects of Market Concentration and Horizontal Mergers on Hospital Costs and Prices, International Journal of Economics Business, vol.159, 180.

[13] Deneckere R. and C. Davidson (1985), Incentives to Form Coalitions with Bertrand Competition, Rand Journal of Economics, vol.16, 473-486.

[14] Economides N. (1989), Symmetric Equilibrium Existence and Optimality in Differentiated Product Markets, Journal of Economic Theory, vol. 47(1), 178194.

[15] Economides N. (1993), Hotelling's "Main Street" with More than Two Competitors, Journal of Regional Science, vol. 33(3), 303-319.

[16] Ganuza J.J. and E. Hauk (2005), Allocating Ideas: Horizontal Competition in Tournaments, Universitat Pompeu Fabra, Working Paper.

[17] Neumann M. and M. Sanderson (2007), Ex post merger review : an evaluation of three competition bureau merger assessments, Final Report, CRA International.

[18] Pautler P.A. (2001), Evidence on Mergers and Acquisitions, Federal Trade Commission Working Paper.

[19] Pita Barros P. (1998), Endogenous mergers and size asymmetry of merger participants, Economics Letters, vol.60, 113-119.

[20] Rothschild R. (2000), Merger under spatial competition, Urban Studies, vol.37, 443-449.

[21] Salop S.C. (1979), Monopolistic Competition with Outside Goods, Bell Journal of Economics, vol.10, 141-156.

[22] Simpson J. and C. Taylor (2008), Do gasoline mergers affect consumer prices ? The Marathon Ashland Petroleum and Ultraman Diamond Shamrock transaction, The Journal of Law and Economics, vol.51, 135-152. 
[23] Socorro P. (2004), Mergers and the importance of fitting well, Economics Letters, vol.82, 269-274.

[24] Salant S., Switzer S. and Reynolds R., (1983), Losses Due to Mergers: The Effects of an Exogenous Change in Industry Structure on Cournot-Nash Equilibrium, Quarterly Journal of Economics, vol.48, 185-200.

[25] Syverson C. (2004), Market Structure and Productivity: A Concrete Example, Journal of Political Economy, vol.112, 1181-1222.

[26] Taylor C. and D. Hosken (2007), The economic effects of the MarathonAshland joint venture: the importance of industry supply shocks and vertical market structure, Journal of industrial Economics, vol.55, 419-451.

[27] Vickrey W. (1964), Microstatics, Harcourt-Brace and World, New York.

[28] Vogel J. (2008), Spatial Competition with Heterogeneous Firms, Journal of Political Economy, vol. 116 (3), 423-466.

[29] Weinberg M. (2008), The Price Effects of Horizontal Mergers, Journal of Competition Law and Economics, vol. 4 (2), 433-447.

[30] Whinston M. (2007), Antitrust Policy Towards Horizontal Mergers. In: M. Armstrong, R. Porter (Eds.). Handbook of Industrial Organization, Vol. III. Amsterdam, North Holland, 2369-2440. 


\section{A Equilibrium regions}

In this appendix we first identify and characterize the equilibrium regions 1am-4am discussed in Section 4.2, then we define regions 1-4 used for the analysis in Section 5.

\section{Regions 1am-4am}

\section{Region 1am}

In this case parameters are such that $v-p_{b m}^{*}>1, v-p_{m}^{*}>1$ and $v-p_{n m}^{*}>1$. The expressions for $p_{m}^{*}$ and $p_{n m}^{*}$ are found by solving the system in (4) and (5). In order to check the prices found are an equilibrium, it has to be shown that: 1) $M$ has no incentive to deviate to a different price; 2) outsider firms do not have an incentive to deviate to a different price; 3) an insider has no incentive to unilaterally deviate.

1) The merger $M$. First, $h$ of the $k$ firms belonging to the merger, $h \leq k$, must not have an incentive to deviate to a higher price as $p_{i}=v-1$ given the price of the other merged and of the non-merging firms is unchanged. This is equivalent to impose:

$$
\frac{d \Pi_{M}}{d \bar{p}}=\sum_{i=1}^{k} \frac{\partial \pi_{i}}{\partial p_{i}} d p_{i} \leq 0
$$

where $d p_{i}=0$ for all the remaining $k-h$ firms that do not change their price. It can be shown that the value of the threshold is independent of $h$ and it is given by:

$$
v \geq v_{1 D}^{m}=\frac{2 N-2 k+3 n-4 N n+k n+k^{2}-1}{(k-n)(2 n+k-2)}
$$

Moreover, in order for an equilibrium to exist for the merged firms, following Chen and Riordan (2007a), it has to be imposed that:

$$
\Pi_{M}^{*} \geq \Pi_{M}^{D}
$$


where: $\Pi_{M}^{*}(h)=h \pi_{i}^{*}$ and $\Pi_{M}^{D}(h)$ is:

$$
\Pi_{M}^{D}=h(v-1) D_{i}\left(p_{m}^{*}+1, p_{m}^{*}, p_{n m}^{*}\right)
$$

where the first price in $D_{i}\left(p_{m}^{*}+1, p_{m}^{*}, p_{n m}^{*}\right)$ represents the price of the $h$ firms that deviate while the other prices refer to the firms that do not deviate. Solving for $v$, it is found that the threshold value $v_{1 U}^{m}(h)$ is monotonically non-increasing in $k$ so the relevant condition is:

$v \leq v_{1 U}^{m}=1+\frac{(2 n-1)^{2}}{(k-n)} \frac{(-2 N+n+1)^{2}}{(k+2 n-2)\left(2 N+2 k-n-4 N n-k n-k^{2}+4 n^{2}-1\right)}$

It follows that the equilibrium for merging firms exist for:

$$
v_{1 D}^{m} \leq v \leq v_{1 U}^{m}
$$

2) Non-merging firm $j(j \in O)$. A possible deviation for one of the outsiders is to raise the price to $p_{j}=v-1$

$$
\left.\frac{\partial \pi_{j}}{\partial p_{j}}\right|_{p_{m}^{*}, p_{n m}^{*}, p_{j}=v-1}=p_{j} \frac{\partial D_{j}}{\partial p_{j}}+\left.D_{j}\right|_{p_{m}^{*}, p_{n m}^{*}, p_{j}=v-1} \leq 0, \forall j \in O
$$

Solving for $v$ drives to the conclusion that it holds if $v \geq v_{1 D}^{n m}$ where:

$$
v_{1 D}^{n m}=\frac{\left(4 N n-2 k N-4 n-k^{2}+3 k\right)}{(2 n+k-2)(n-k)}
$$

Moreover, in order for an equilibrium to exist for the non-merged firms it has to be imposed that:

$$
\pi_{j}^{*} \geq \pi_{j}^{D}, \forall j \in O
$$

where $\pi_{j}^{D}$ is:

$$
\pi_{j}^{D}=(v-1) D_{j}\left(p_{n m}^{*}+1, p_{m}^{*}\right), \forall j \in O
$$

Solving for $v$, it is found that this condition holds for:

$$
v \leq v_{1 U}^{n m}=1+\frac{(2 n-k)^{2}(n-2 N+1)^{2}}{(n-k)(2-k-2 n)\left(k+2 N k-4 N n-2 k n-k^{2}+4 n^{2}\right)}
$$


It follows that the equilibrium for non-merging firms exist for:

$$
v_{1 D}^{n m} \leq v \leq v_{1 U}^{n m}
$$

3) Merged firms $i,(i \in I)$. As a unilateral deviation of an insider firm is considered, the externality effect of deviation on other merged firms is not relevant. The condition that makes such a deviation not profitable is then:

$$
\left.\frac{\partial \pi_{1}}{\partial p_{1}}\right|_{p_{1}=v-1}=p_{1} \frac{\partial D_{1}}{\partial p_{1}}+\left.D_{1}\right|_{p_{i}=v-1, p_{m}^{*}, p_{n m}^{*}} \leq 0, \forall i \in I
$$

from which it is found:

$$
v \geq v_{1 D}^{i n s}=\frac{(2 n-1)}{2} \frac{2 N-3 k+3 n+2 N k-4 N n+k^{2}-1}{(n-1)(k-n)(k+2 n-2)}
$$

Moreover, in order for an equilibrium to exist for the merged firms, following

Chen and Riordan (2007a), it has to be imposed that:

$$
\pi_{i}^{*} \geq \pi_{i}^{D}, \forall i \in I
$$

where $\pi_{i}^{D}$ is:

$$
\pi_{i}^{D}=(v-1) D_{i}\left(p_{m}^{*}+1, p_{m}^{*}, p_{n m}^{*}\right)
$$

It can be noticed that the condition is different from the analog $\left(\Pi_{M}^{*} \geq\right.$ $\left.\Pi_{M}^{D}\right)$ used at point 1 ) as only one firm now deviates and this impacts on $D_{i}\left(p_{m}^{*}+1, p_{m}^{*}, p_{n m}^{*}\right)$. Solving the inequality it is found:

$v \leq v_{1 U}^{i n s}=1+\frac{(2 n-1)^{2}}{(k-n)} \frac{(2 N-n-1)^{2}}{(2 n+k-2)\left(2 N-k-3 n-4 N n+k n+4 n^{2}+1\right)}$

Notice further that $v_{1 U}^{i n s}>v_{1 U}^{m}$ as both can be found as special cases of the function $v_{1 U}^{m}(h)$ which is decreasing in $h$. To conclude, the equilibrium for merging firms exist for:

$$
v_{1 D}^{i n s} \leq v \leq v_{1 U}^{i n s}
$$


Bringing together all the information, it can be verified that an equilibrium for the after merger and for both merged and non-merged firms exists for the following values of $v$ :

$$
v_{1 D}^{a m}=\max \left\{v_{1 D}^{m}, v_{1 D}^{n m}, v_{1 D}^{i n s}\right\} \leq v \leq \min \left\{v_{1 U}^{b m}, v_{1 U}^{m}, v_{1 U}^{i n s}\right\}=v_{1 U}^{a m}
$$

Region 2am

In this case the parameters are such that: $v-p_{b m}^{*}=1, v-p_{m}^{*}=1$ and $v-p_{n m}^{*}=1$, hence the prices are immediately determined. The equilibrium regions are identified as follows.

1) Merger $M$. It must be ruled out that a group of $h$ of the $k$ firms composing $M, h \leq k$, has an incentive to raise her price to $p_{i}>v-1$ or decrease it to $p_{i}<v-1$.

Consider a price increase, in that case the demand faced by the deviating firms is as if they were in Region 3, given the other firms stick to their equilibrium prices. This is not profitable if:

$$
\frac{d \Pi_{M}}{d \bar{p}}=\left.\sum_{i=1}^{k} \frac{\partial \pi_{i}}{\partial p_{i}} d p_{i}\right|_{p_{i}>v-1, p_{m}^{*}, p_{n m}^{*}} \leq 0, \forall i \in I
$$

where $d p_{i}=0$ for all the remaining $k-h$ firms that do not change their price. It can be shown that the value of the threshold is increasing in $h$ which implies one can focus on the case $h=k$; this leads to:

$$
v \geq v_{2 D}^{m}=\frac{4 N-2 n-k-1}{2 N-n-k}
$$

Consider instead a price decrease, in that case the demand faced by the $h$ deviating firms is as if they were in Region 1, given the other firms stick to their equilibrium prices. This is not profitable if:

$$
\frac{d \Pi_{M}}{d \bar{p}}=\left.\sum_{i=1}^{k} \frac{\partial \pi_{i}}{\partial p_{i}} d p_{i}\right|_{p_{i}<v-1, p_{m}^{*}, p_{n m}^{*}} \leq 0, \forall i \in I
$$


where $d p_{i}=0$ for all the remaining $k-h$ firms that do not change their price. It can be shown that the value of the threshold is decreasing in $h$; hence, it makes sense to focus on the case $h=k$ which implies the relevant threshold is:

$$
v \leq v_{2 U}^{m}=\frac{2 N-k-1}{n-k}
$$

2) Turn now to a given non-merging firm. An analogous reasoning allows to rule out possible deviations. Suppose in particular that firm $j$ raises her price to $p_{j}>v-1$. In that case the demand faced by the firm is as if she was in Region 3. In order for this not to be profitable it must be:

$$
\left.\frac{\partial \pi_{j}}{\partial p_{j}}\right|_{p_{m}^{*}, p_{n m}^{*}, p_{j}>v-1}=p_{j} \frac{\partial D_{j}}{\partial p_{j}}+\left.D_{j}\right|_{p_{m}^{*}, p_{n m}^{*}, p_{j}>v-1} \leq 0, \forall j \in O
$$

which in turn implies:

$$
v \geq v_{2 D}^{n m}=2
$$

If firm $j$ decreases her price, instead, to $p_{j}<v-1$. In that case the demand faced by the firm is as if she was in Region 1 . In order for this not to be profitable it must be:

$$
\left.\frac{\partial \pi_{j}}{\partial p_{j}}\right|_{p_{m}^{*}, p_{n m}^{*}, p_{j}<v-1}=p_{j} \frac{\partial D_{j}}{\partial p_{j}}+\left.D_{j}\right|_{p_{m}^{*}, p_{n m}^{*}, p_{j}<v-1} \leq 0, \forall j \in O
$$

implying:

$$
v \leq v_{2 U}^{n m}=2 \frac{N-1}{n-1}
$$

3) The same values as above can be found for a merging firm $i, i \in I$, to rule out she has a unilateral incentive to increase or decrease their price. Hence:

$$
v_{2 D}^{n m}=v_{2 D}^{i n s} \leq v \leq v_{2 U}^{i n s}=v_{2 U}^{n m}
$$

Bringing together all the information, it is verified that an equilibrium which is incentive compatible before and after merger and for both merged and non-merged firms exists for the following subset of values of $v$ :

$$
v_{2 D}^{a m}=\max \left\{v_{2 D}^{m}, v_{2 D}^{n m}, v_{2 D}^{i n s}\right\} \leq v \leq \min \left\{v_{2 U}^{m}, v_{2 U}^{n m}, v_{2 U}^{i n s}\right\}=v_{2 U}^{a m}
$$


Region 3am

In this case the parameters are such that: $\frac{1}{2}<v-p_{b m}^{*}<1, \frac{1}{2}<v-p_{m}^{*}<$ 1 and $\frac{1}{2}<v-p_{n m}^{*}<1$. The expressions for $p_{m}^{*}$ and $p_{n m}^{*}$ are found by solving the system in (4) and (5). It has to be verified for what values of $v$ there are no incentives to deviate. In this case there are two possible deviations for the merged firms and for the non-merged: they can potentially deviate either to $p=v-1$ or to $p=v-\frac{1}{2}$.

1) Merger $M$. Suppose $h$ of the $k$ firms belonging to the merger $M$, $h \leq k$, want to deviate to a higher price as $p_{i}=v-\frac{1}{2}$ given that the price of the other merged and of the non-merging firms is unchanged. They do not have an incentive to do so if:

$$
\frac{d \Pi_{M}}{d \bar{p}}=\sum_{i=1}^{k} \frac{\partial \pi_{i}}{\partial p_{i}} d p_{i} \leq 0
$$

where $d p_{i}=0$ for all the remaining $k-h$ firms that do not change their price. It can be shown that the value of the threshold is increasing in $h$ so it makes sense to focus on the case $h=k$. This leads to find the following threshold :

$$
v>v_{3 D}^{m}=v_{3 D}^{m}(N, n, k)
$$

Suppose instead the same $h$ of the $k$ firms belonging to the merger $M$, $h \leq k$, want to deviate to a lower price as $p_{i}=v-1$, given that the price of the other merged and of the non-merging firms is unchanged. They do not have an incentive to do so if:

$$
\frac{d \Pi_{M}}{d \bar{p}}=\sum_{i=1}^{k} \frac{\partial \pi_{i}}{\partial p_{i}} d p_{i} \geq 0
$$

where $d p_{i}=0$ for all the remaining $k-h$ firms that do not change their price. It can be shown that the value of the threshold is increasing in $h$ so 
it makes sense to focus on the case $h=1$. This leads to find the following threshold :

$$
v \leq v_{3 U}^{m}=v_{3 U}^{m}(N, n, k)
$$

It follows that the equilibrium for merging firms exist for:

$$
v_{3 D}^{m} \leq v \leq v_{3 U}^{m}
$$

2) Non-merging firms. If one of the non-merged firms, say $j(j \in O)$, tries to deviate it will cut her price to $p_{j}=v-1$ then for the deviation not to be profitable it must be:

$$
\left.\frac{\partial \pi_{j}}{\partial p_{j}}\right|_{p_{m}^{*}, p_{n m}^{*}, p_{j}=v-1}=p_{j} \frac{\partial D_{j}}{\partial p_{j}}+\left.D_{j}\right|_{p_{m}^{*}, p_{n m}^{*}, p_{j}=v-1} \geq 0, \forall j \in O
$$

Solving for $v$ drives to the conclusion that it holds if $v \leq v_{3 U}^{n m}$ where:

$$
v_{3 U}^{n m}=\frac{1}{2} \frac{16 N^{2}-12 N n-4 N k-12 N+2 n^{2}+n k+6 n-k^{2}+4 k}{8 N^{2}-8 N n-2 N k-4 N+2 n^{2}+n k+2 n-k^{2}+2 k}
$$

On the other hand, if $j$ raises her price to $p_{j}=v-\frac{1}{2}$ then the following has to be imposed:

$$
\left.\frac{\partial \pi_{j}}{\partial p_{j}}\right|_{p_{m}^{*}, p_{n m}^{*}, p_{j}=v-\frac{1}{2}}=p_{j} \frac{\partial D_{j}}{\partial p_{j}}+\left.D_{j}\right|_{p_{m}^{*}, p_{n m}^{*}, p_{j}=v-\frac{1}{2}} \leq 0, \forall j \in O
$$

Solving for $v$ drives to the conclusion that it holds if $v \geq v_{3 D}^{n m}$ where:

$$
v_{3 D}^{n m}=\frac{16 N^{2}-16 N n-4 N k-8 N+4 n^{2}+2 n k+4 n-k^{2}+3 k}{8 N^{2}-8 N n-2 N k-4 N+2 n^{2}+n k+2 n-k^{2}+2 k}
$$

It follows that the equilibrium for non-merging firms exist for:

$$
v_{3 D}^{n m} \leq v \leq v_{3 U}^{n m}
$$

3) Merged firms $i(i \in I)$. One of the firms taking part to $M$ does not have an incentive to deviate unilaterally to a higher price $p_{i}=v-\frac{1}{2}$ if: 


$$
\left.\frac{\partial \pi_{i}}{\partial p_{i}}\right|_{p_{i}=v-\frac{1}{2}}=p_{i} \frac{\partial D_{i}}{\partial p_{i}}+\left.D_{i}\right|_{p_{i}=v-\frac{1}{2}, p_{m}^{*}, p_{n m}^{*}} \leq 0, \forall i \in I
$$

leading to:

$$
v \geq v_{3 D}^{i n s}=v_{3 D}^{i n s}(N, n, k)
$$

Suppose instead the firm decides to unilaterally decrease the price to $p_{i}=v-1$; this is not profitable if:

$$
\left.\frac{\partial \pi_{i}}{\partial p_{i}}\right|_{p_{i}=v-1}=p_{i} \frac{\partial D_{i}}{\partial p_{i}}+\left.D_{i}\right|_{p_{i}=v-1, p_{m}^{*}, p_{n m}^{*}} \geq 0, \forall i \in I
$$

solving which it is found:

$$
v \leq v_{3 U}^{i n s}=v_{3 U}^{i n s}(N, n, k)
$$

Bringing together all the information, it is verified that an equilibrium after merger and for both merged and non-merged firms exists for the following values of $v$ :

$$
v_{3 D}^{a m}=\max \left\{v_{3 D}^{m}, v_{3 D}^{n m}, v_{3 D}^{i n s}\right\} \leq v \leq \min \left\{v_{3 U}^{m}, v_{3 U}^{n m}, v_{3 U}^{i n s}\right\}=v_{3 U}^{a m}
$$

\section{Region $4 a m$}

In this case the parameters are such that: $v-p_{b m}^{*}=\frac{1}{2}, v-p_{m}^{*}=\frac{1}{2}$ and $v-p_{n m}^{*}=\frac{1}{2}$, so prices are immediately determined. The equilibrium regions are identified as follows.

1) Merger $M$. Focus first on a given merging firm, say $i(i \in I)$. It must be ruled out that she has an incentive to raise her price to $p_{i}>v-\frac{1}{2}$ or decrease it to $p_{i}<v-\frac{1}{2}$. Consider a price increase, in that case the demand faced by the firm is as if she was a local monopolist, given the other firms stick to their equilibrium prices. This is not profitable if:

$\left.\frac{\partial \pi_{i}}{\partial p_{i}}\right|_{p_{i}>v-\frac{1}{2}, p_{m}^{*}, p_{n m}^{*}}=p_{i} \frac{\partial D_{i}}{\partial p_{i}}+D_{i}+\left.(k-1) p_{m}^{*} \frac{\partial D_{m}}{\partial p_{i}}\right|_{p_{i}>v-\frac{1}{2}, p_{m}^{*}, p_{n m}^{*}} \leq 0, \forall i \in I$ 
which implies:

$$
v \geq v_{4 D}^{m}=1
$$

Consider instead a price decrease, in that case the demand faced by firm $i$ is as if they were in Region 3, given the other firms stick to their equilibrium prices. This is not profitable if:

$\left.\frac{\partial \pi_{i}}{\partial p_{i}}\right|_{p_{i}>v-\frac{1}{2}, p_{m}^{*}, p_{n m}^{*}}=p_{i} \frac{\partial D_{i}}{\partial p_{i}}+D_{i}+\left.(k-1) p_{m}^{*} \frac{\partial D_{m}}{\partial p_{i}}\right|_{p_{i}<v-\frac{1}{2}, p_{m}^{*}, p_{n m}^{*}} \leq 0, \forall i \in I$ implying:

$$
v \leq v_{4 U}^{m}=\frac{1}{2} \frac{4 N-n-k-2}{2 N-n-1}
$$

2) Turn now to any of the non-merging firms. An analogous reasoning allows to rule out possible deviations. Suppose in particular that firm $j$ $(j \in O)$ raises her price to $p_{j}>v-\frac{1}{2}$. In that case the demand faced by the firm is the one of a local monopolist. In order for this not to be profitable it must be:

$$
\left.\frac{\partial \pi_{j}}{\partial p_{j}}\right|_{p_{m}^{*}, p_{n m}^{*}, p_{j}>v-\frac{1}{2}}=p_{j} \frac{\partial D_{j}}{\partial p_{j}}+\left.D_{j}\right|_{p_{m}^{*}, p_{n m}^{*}, p_{j}>v-\frac{1}{2}} \leq 0, \forall j \in O
$$

which in turn implies:

$$
v \geq v_{4 D}^{n m}=1
$$

If firm $j$ decreases her price, instead, to $p_{j}<v-\frac{1}{2}$. In that case the demand faced by the firm is as if she was in Region 3 . In order for this not to be profitable it must be:

$$
\left.\frac{\partial \pi_{j}}{\partial p_{j}}\right|_{p_{m}^{*}, p_{n m}^{*}, p_{j}<v-\frac{1}{2}}=p_{j} \frac{\partial D_{j}}{\partial p_{j}}+\left.D_{j}\right|_{p_{m}^{*}, p_{n m}^{*}, p_{j}<v-\frac{1}{2}} \leq 0, \forall j \in O
$$

implying:

$$
v \leq v_{4 U}^{n m}=\frac{1}{2} \frac{4 N-n-3}{2 N-n-1}
$$

3) The same values as above can be found for a merging firm $i, i \in I$, to rule out she has a unilateral incentive to increase or decrease their price. Hence:

$$
v_{4 D}^{n m}=v_{4 D}^{i n s} \leq v \leq v_{4 U}^{i n s}=v_{4 U}^{n m}
$$


Bringing together all the information, it is verified that an equilibrium after merger and for both merged and non-merged firms exists for the following values of $v$ :

$$
v_{4 D}^{a m}=\max \left\{v_{4 D}^{m}, v_{4 D}^{n m}, v_{4 D}^{i n s}\right\} \leq v \leq \min \left\{v_{4 U}^{m}, v_{4 U}^{n m}, v_{4 U}^{i n s}\right\}=v_{4 U}^{a m}
$$

\section{Regions 1-4}

Regions 1 to 4 are defined by the intersection of regions $1 \mathrm{bm}-4 \mathrm{bm}$ and with the regions 1am-4am just identified. Recalling that Regions $1 \mathrm{bm}-4 \mathrm{bm}$ were defined as follows:

$$
\begin{aligned}
v_{1 D}^{b m} & =\frac{2(N-1)}{n-1} \leq v \leq 2 \frac{N-1}{n-1}+\frac{(2 N-n-1)}{2(N-n)}=v_{1 U}^{b m} \\
v_{2 D}^{b m} & =2 \leq v \leq 2 \frac{N-1}{n-1}=v_{2 U}^{b m} \\
v_{3 D}^{b m} & =\frac{1}{2} \frac{4 N-n-3}{2 N-n-1} \leq v \leq 2=v_{3 U}^{b m} \\
v_{4 D}^{b m} & =1 \leq v \leq \frac{1}{2} \frac{4 N-n-3}{2 N-n-1}=v_{4 U}^{b m}
\end{aligned}
$$

Region 1-4 are then defined for the following values of $v$ :

$$
v_{l D}=\max \left\{v_{l D}^{b m}, v_{l D}^{a m}\right\} \leq v \leq \min \left\{v_{l U}^{b m}, v_{l U}^{a m}\right\}=v_{l U}
$$

where $l=1 . .4$. 


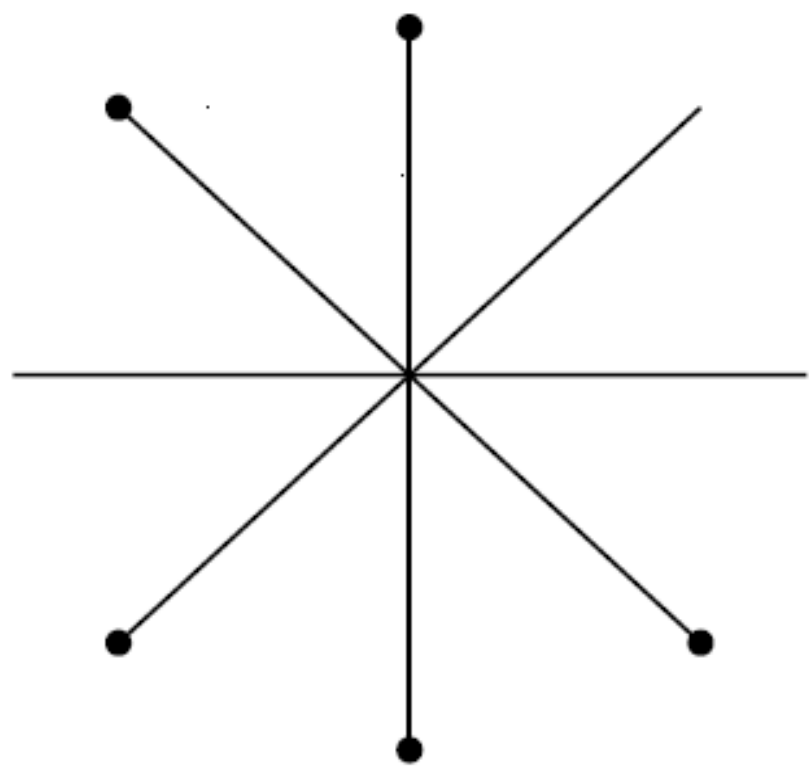

Figure 1. The Spokes Model, Chen-Riordan (2007), $n=5, N=8$. 


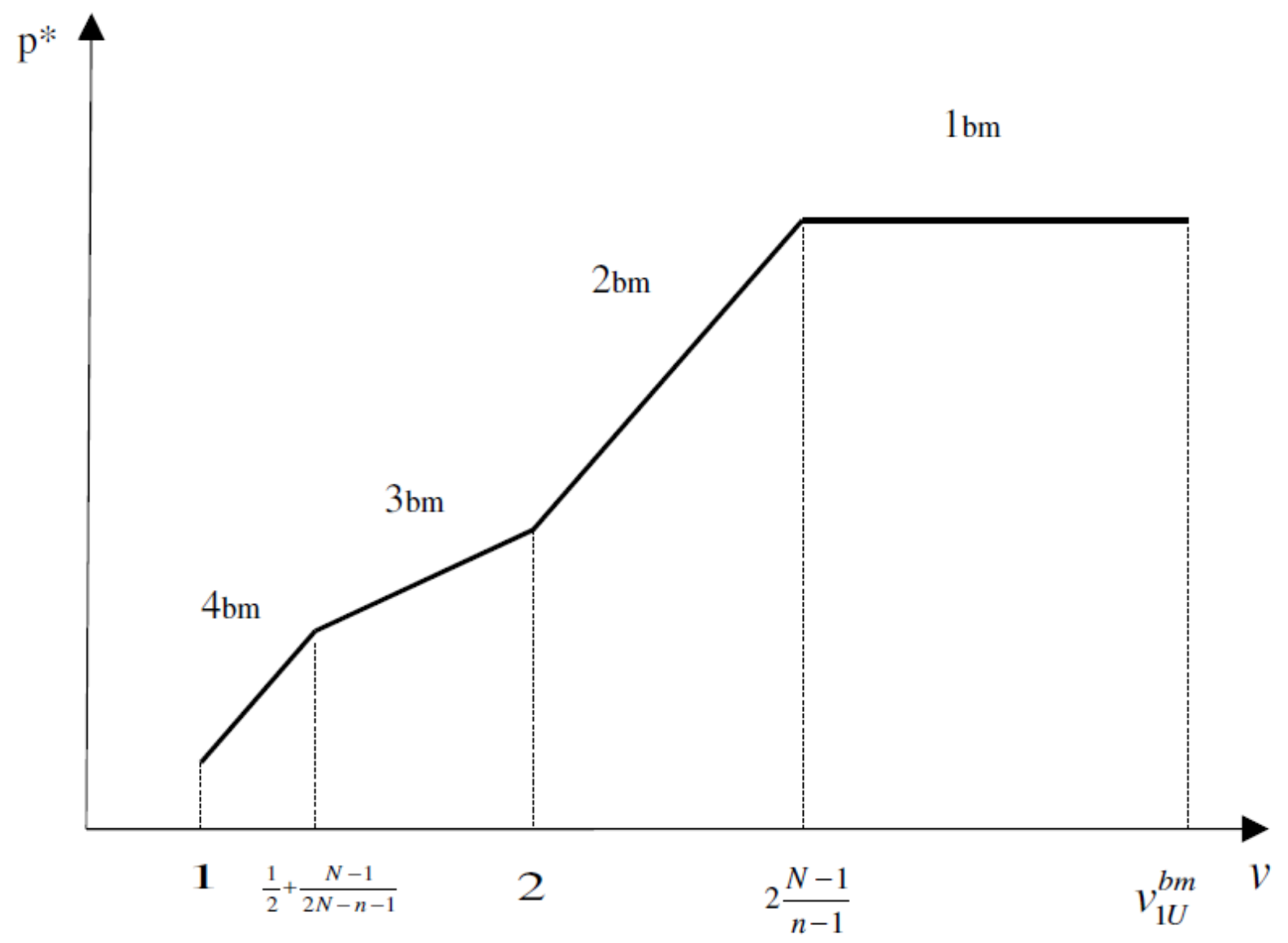

Figure 2. The before merger equilibrium prices, Chen-Riordan (2007). 


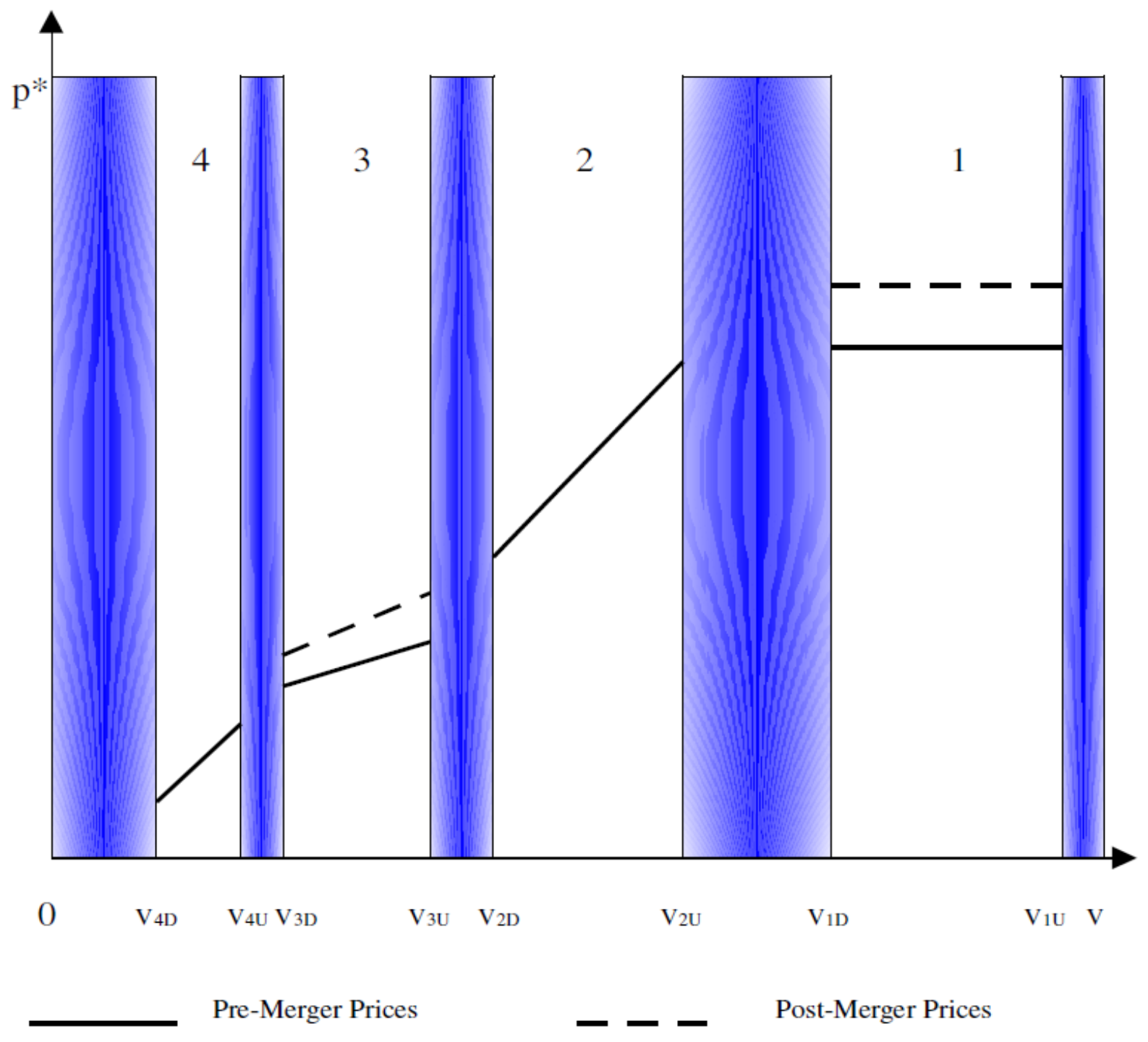

Figure 3 . The after merger equilibrium prices. 